\title{
Alinhamento da gestão de processos com os mecanismos do modelo de governança pública do TCU: o estudo de caso em uma universidade federal da Amazônia Oriental
}

\author{
Alan Carlos Pereira da Costa \\ Universidade Federal do Amapá (Unifap) \\ Ana Flavia Pacheco Leal \\ Universidade Federal do Amapá (Unifap) \\ Lana Caroline Barbosa do Nascimento \\ Universidade Federal do Amapá (Unifap)
}

Cláudio Márcio Campos de Mendonça

Universidade Federal do Amapá (Unifap)

Lenin Cavalcanti Brito Guerra

Instituto Federal do Rio Grande do Norte (IFRN)

O objetivo deste trabalho foi identificar as relações existentes entre os mecanismos de Governança Pública do Tribunal de Contas da União (TCU) e a implementação de uma gestão de processos no âmbito da Universidade Federal do Amapá. Do ponto de vista metodológico, quanto aos fins, este estudo é descritivo e exploratório, com abordagem ao problema ocorrendo de forma qualitativa; quantos aos meios, pode ser caracterizado como um estudo de caso. Na coleta de dados, elaborou-se um instrumento de pesquisa à luz dos mecanismos de governança pública do TCU e foram realizadas entrevistas semiestruturadas com os principais gestores da Unifap. No tratamento dos dados coletados, foi realizada análise de conteúdo. Os resultados apontaram relação entre a adoção de uma gestão de processos com os mecanismos de governança pública apresentados pelo TCU (2014), de modo que os processos permitem à governança maior transparência quanto às atividades executadas, definição das competências entre os atores do processos, e identificação de falhas.

Palavras-chave: gestão de processos - implementação, governança, transparência governamental, accountability, administração pública

[Artigo recebido em 23 de dezembro de 2017. Aprovado em 31 de julho de 2018.] 
Alineamiento de la gestión de procesos con los mecanismos del modelo de gobernanza pública del Tribunal de Cuentas de Brasil (TCU): el estudio de caso en una universidad federal de Amazonia Oriental

El objetivo de este trabajo fue identificar las relaciones entre la gestión de procesos utilizando BPMN y los mecanismos de Gobernanza Pública del Tribunal de Cuentas de Brasil (TCU) en una Universidad Pública de la Amazonía Oriental brasileña. Desde el punto de vista metodológico, en cuanto a los fines, este estudio es descriptivo y exploratorio, con abordaje al problema ocurriendo de forma cualitativa, y cuántos a los medios, puede ser caracterizado como un estudio de caso. En la recolección de datos, se elaboró un instrumento de investigación a la luz de los mecanismos de gobierno público del TCU y se llevaron a cabo entrevistas semiestructuradas con los principales gestores de Unifap. En el tratamiento de los datos recolectados, se realizó análisis de contenido. Los resultados señalaron una relación entre la adopción de una gestión de procesos con los mecanismos de gobernanza pública presentados por el TCU (2014), de modo que los procesos permiten la gobernanza, mayor transparencia en cuanto a las actividades ejecutadas, definición de las competencias entre los actores del proceso, identificación de fallos.

Palabras clave: gestión de procesos - implementación, gobernanza, transparencia gubernamental, accountability, administración pública

Process management alignment with Brazilian State Audit Cort (TCU) public governance model mechanisms: a case study in a East Amazon Federal University

This article's objective was to identify relations between Brazilian State Audit Cort (TCU) Public Governance mechanisms and process management implementation in brazilian's Amapá Public University (Unifap). In relation to methodology, by the purposes, this research is descriptive and exploratory, and by the means, it can be characterized as a case study. In the data collect, a research instrument was elaborated in light of TCU's public governance and semi structured interviews were done to the main managers of each of Unifap area. In collected data treatment, it was used the content analysis. The results pointed the relation between adoption of a process management and public governance mechanisms presented by the TCU (2014), so that the processes, allows the governance, bigger transparency to the activities performed, defining the competencies among the processes' actors and failures identification.

Keywords: process management - implementation, governance, government transparency, accountability, public administration 


\section{Introdução}

Diante do processo de transformação como característica do contexto atual, Martins e Marini (2010) apontam que a globalização e a revolução tecnológica, além de outros fatores, modificam o papel do Estado e exigem novas concepções de gestão pública. No esteio da difusão da cultura gerencial e da crise do Estado, sobretudo a partir dos anos 1970, a necessidade de tornar o Estado mais eficiente possibilitou a ascensão de modelos como a Nova Administração Pública, que trouxeram para o setor público a lógica do foco nos resultados, a partir da adoção de ferramentas gerenciais advindas do setor privado.

Já nos anos 90, esse contexto propiciou discutir a governança na esfera pública e resultou no estabelecimento dos princípios básicos que norteiam as boas práticas de governança nas organizações públicas (IFAC, 2013): transparência, integridade e prestação de contas.

No contexto brasileiro, o Tribunal de Contas da União (TCU), órgão de controle externo do Governo Federal que auxilia o Congresso Nacional no acompanhamento da execução orçamentária e financeira do país, estabeleceu formalmente os princípios da governança pública brasileira. Para garantir avaliação, direcionamento e monitoramento, as práticas de gestão pública devem adotar mecanismos de liderança, a qual refere-se ao conjunto de práticas relacionadas aos aspectos humanos ou comportamentais; de estratégia, que considera a avaliação do ambiente interno e externo da organização, a construção de cenários, definição e operacionalização da estratégia; de controle, que estimulem a transparência e a accountability, com o objetivo de conduzir às políticas públicas e à prestação de serviços de interesse da população (TRIBUNAL DE CONTAS DA UNIÃO, 2014).

Uma das ferramentas que auxilia a implementação de uma gestão pública baseada nos princípios da governança pública é o gerenciamento de processos, que tem na Business Management Process Notation (BPMN) uma das abordagens mais utilizadas. Para Campos e Lima (2012), o mapeamento de processos possibilita ao gestor a macro compreensão do fluxo operacional e as relações entre as diversas etapas do processo e a identificação dos pontos fortes e fracos, maximizando o desempenho organizacional.

O BPMN tem sido utilizado por diversas organizações públicas, sobretudo após a criação do Programa Nacional de Gestão Pública e Desburocratização (Gespública), em fevereiro de 2005, com a finalidade de "contribuir para a melhoria da qualidade dos serviços públicos prestados aos cidadãos e para o aumento da competitividade do País", que tem como um de seus fundamentos a "Orientação por processos e Informações" (BRASIL, 2005). Um dos documentos 
gerados pelo Gespública é o “Guia 'd' - Simplificação Administrativa e de Gestão de Processos", manual desenvolvido para auxiliar na melhoria das rotinas e para o aprimoramento da gestão interna dos órgãos.

As Instituições Federais de Educação Superior (IFES), como autarquias federais, também têm adotado procedimentos de gestão alinhados à governança pública, como a BPMN. Este estudo foi desenvolvido na Universidade Federal do Amapá (Unifap), instituição de ensino superior situada no norte do Brasil, em uma região conhecida como Amazônia Oriental. O artigo objetiva identificar as relações existentes entre os mecanismos de Governança Pública do TCU e a implementação de uma gestão de processos no âmbito da Universidade Federal do Amapá. Para preservar os entrevistados, ocupantes de cargos de Reitoria ou Pró-reitoria, optouse por não revelar seus nomes.

Além desta seção introdutória, o referencial teórico aborda temas como a governança pública, seus mecanismos e componentes, processos, gestão de processos e por processos e processos na gestão pública; na metodologia apresentase o percurso metodológico do estudo. A análise dos resultados está dividida de acordo com os mecanismos de governança estabelecidos pelo TCU: liderança, estratégia e controle; as considerações finais apontam as principais conclusões obtidas com a pesquisa.

\section{Referencial teórico}

\section{Governança pública}

Há na literatura diversos conceitos sobre governança, sendo dificultoso caracterizar de forma uniforme ou padronizar a definição acerca dessa temática devido à multiplicidade de conceitos (SILVA; SENNA; LIMA JUNIOR, 2014); portanto, essa definição não se coloca livre de contestações (SECCHI, 2009). Segundo o TCU (2014), a governança ligada ao setor público compreende, sobretudo, os mecanismos de liderança, estratégia e controle colocados em prática para avaliar, direcionar e monitorar o comportamento da gestão.

O conceito de governança surgiu no âmbito privado, a partir da necessidade dessas organizações de disponibilizarem ao mercado, em especial aos acionistas, informações além daquelas previstas como obrigatórias na legislação. A adoção desse modelo induziu as empresas privadas a seguirem certos princípios, como equidade, transparência, accountability, compliance e definição de responsabilidades (SCOLFORO, 2013). A principal motivação que conduziu à adaptação da governança corporativa aplicada ao setor público consiste na dificuldade que o Estado tem 
de efetivar suas práticas, que, por vezes, são vagarosas e intransigentes, o que influencia diretamente da qualidade dos serviços oferecidos à população (MATIASPEREIRA, 2010).

De acordo com o International Federation of Accountants (IFAC) (2013), governança pública pode ser compreendida como todos os mecanismos (administrativos, legais, políticos etc) que são colocados em prática para garantir que os resultados desejados pelas partes interessadas sejam primeiramente definidos e alcançados. Em um ambiente pautado na ética, Fortini e Shermam (2017) enfatizam que a governança pública torna-se fundamental para o incremento da eficiência e para a diminuição de comportamentos de gestores públicos em desacordo com as boas práticas administrativas, bem como assume o papel de fiscalizar e regular suas ações.

De modo geral, governança pública consiste no sistema que determina o equilíbrio e repartição do poder entre os envolvidos, como cidadão, governantes, alta administração, gestores e colaboradores, de modo a permitir que o bem comum e o interesse da coletividade prevaleçam sobre os interesses ou anseios de pessoas ou grupos (MATIAS-PEREIRA, 2010). Contribuindo com esse entendimento, Moraes Filho (2015) coloca que governança pública também pode ser entendida como um conjunto de princípios e estratégias empregadas pelos gestores públicos que auxiliam na condução das políticas públicas, fornecendo orientação para a tomada de decisão e buscando a maximização dos resultados e minimização das problemáticas.

\section{Mecanismos e componentes de governança pública do TCU}

Para que as funções que compõem a governança sejam realizadas de modo adequado, o TCU (2014) afirma que é necessária a adoção de alguns mecanismos de governança (liderança, estratégia e controle) e seus respectivos componentes, descritos abaixo:

\section{Mecanismo liderança}

Diz respeito a uma série de práticas, humanas ou comportamentais, que permitam requisitos mínimos para o exercício da governança, práticas essas como: pessoas capacitadas, motivadas, com condutas éticas adequadas e que assumam as principais funções da organização e liderem os trabalhos (TRIBUNAL DE CONTAS DA UNIÃO, 2014). A liderança é um dos temas essenciais para a boa governança pública e envolve alguns aspectos formais como separação dos poderes, sistema de controle e avaliação, dentre outros (ORGANIZAÇÃo DE COOPERAÇÃo E DE DESENVOLVIMENTO ECONÔMICO, 2002). Esse mecanismo possui 4 componentes, que 
serão apresentados abaixo:

a. Pessoas e Competências: trata sobre as pessoas que trabalham na organização, as competências que possuem, conhecimentos, habilidades e atitudes dos dirigentes, que, no âmbito da organização, devem ser direcionados aos resultados (TRIBUNAL DE CONTAS DA UNIÃO, 2014). Além disso, a escolha dos membros da alta administração deve ser embasada na busca gestores que possuam a competência necessária de acordo com a função (NASCIMENTO; AGUIAR, 2015).

b. Princípios e Comportamentos: na busca constante da excelência nos serviços prestados, as organizações devem contar com pessoas que, além de devidamente capacitadas, apresentem conduta ética adequada. Para tal, pode-se adotar um código de ética para definição de condutas e mecanismos de controle que evitem determinadas ações desviantes (TRIBUNAL DE CONTAS DA UNIÃO , 2014).

c. Liderança Organizacional: esse componente perpassa pela delegação de competências e coordenação das estruturas das unidades (PENEDo; QUELHAS, 2016); a partir de então, as chefias passam a planejar, organizar e executar ações que contribuam para o cumprimento dos objetivos e metas organizacionais, sendo que a responsabilidade final pelos atos delegados permanece com o gestor máximo (TRIBUNAL DE CONTAS DA UNIÃO, 2014).

d. Sistemas de Governança: compreende a forma como os diversos atores que participam da governança organizam-se, relacionam-se e comportam-se para o alcance da boa governança. Envolve, no setor público, as estruturas e os processos que estão diretamente envolvidos com as instâncias internas, externas a governança (TRIBUNAL DE CONTAS DA UNIÃO, 2014).

\section{Mecanismo Estratégia}

O mecanismo estratégia está dividido em três componentes e trata do processo de tomada de decisão para definição dos rumos da organização, por meio da avaliação e prospecção de cenários, identificação das necessidades e expectativas dos stakeholders e alinhamento organizacional, entre outros (TRIBUNAL DE CONTAS DA UNIÃO, 2014).

a. Relacionamento com as partes interessadas: aborda a respeito de como a organização deve manter os stakeholders alinhados com os objetivos da instituição, envolvendo-os para a melhor identificação das necessidades e expectativas. Como resultado almejado, espera-se um relacionamento considerado adequado por diversas partes, bem como o equilíbrio e a 
promoção dos dados e informações aos interessados (TRIBUNAL DE CONTAS DA UNIÃo , 2014). Complementando esse entendimento, o Instituto Brasileiro de Governança Corporativa (IBGC) (2015) e Mello (2006) colocam como fundamental que os agentes da governança formulem estratégias de comunicação com as partes interessadas, com a disseminação de políticas, procedimentos, práticas e normas da organização, de modo equitativo (BRASIL, 2017).

b. Estratégia organizacional: discorre acerca da escolha do modelo da estratégia organizacional, para que esta compreenda as partes interessadas já citadas na sua formulação e definição de objetivos, viabilizando a eficiência e eficácia ao atingir os propósitos definidos, além de incluir o processo de avaliação dos resultados (TRIBUNAL DE CONTAS DA UNIÃO, 2014). A importância desse componente está na impossibilidade de se falar na governança em instituições que não tenham a estratégia delineada e que não possuam objetivos definidos (KRÜGER, 2016).

c. Alinhamento transorganizacional: desenvolve sobre como as instituições devem estar relacionadas de maneira transorganizacional, com objetivos e propósitos que possam se impulsionar e fortalecer, com a utilização de mecanismos que possam propiciar a atuação uniforme e cooperada para que todos os atores possam colaborar com a missão da empresa de maneira coerente (TRIBUNAL DE CONTAS DA UNIÃO, 2014). Estimula as organizações a trabalharem de modo conjunto para a elaboração e condução de políticas públicas (OLIVEIRA, 2015).

\section{Mecanismo controle}

O mecanismo controle engloba uma série de práticas que procuram garantir que a organização está tomando o rumo inicialmente estabelecido, conforme a estratégia (OlIVEIRA, 2015), avaliando e tratando os riscos de modo adequado (TRIBUNAL DE CONTAS DA UNIÃo, 2014). Esse mecanismo é formado por três componentes que serão apresentados abaixo.

a. Gestão de riscos e controle interno: refere-se a definir quais riscos são aceitáveis a cada natureza das atividades (TRIBUNAL DE CONTAS DA UNIÃO, 2014). Com o crescimento organizacional, as organizações têm necessidade da implantação de mecanismos de controles mais fortes, uma vez que o administrador não pode supervisionar pessoalmente cada atividade desempenhada pelos colaboradores (LÉLIS; MARIO, 2009). Portanto, as organizações devem buscar definir critérios de gestão de riscos, bem como manter o processo monitorado e avaliado, visando minimizar impactos 
negativos e assegurando um melhor desempenho (TRIBUNAL DE CONTAS DA UNIÃO, 2014).

b. Auditoria interna: responsável por auxiliar a gestão quanto à adequação do controle de riscos e prevenção a fraudes executado no ambiente, tendo papel essencial de apoio à administração no que se refere à conduta dos servidores e desenvolvimento dos processos por meio de sugestões de aperfeiçoamento e orientações (TRIBUNAL DE CONTAS DA UNIÃO, 2017). Portanto, para o cumprimento do resultado esperado, a organização deve determinar a função e posição da auditoria interna, definindo suas atividades, viabilizando sua independência e que esta contribua efetivamente com a melhoria do desempenho dos processos (TRIBUNAL DE CONTAS DA UNIÃO, 2014).

C. Accountabilityetransparência:oTCU(2014)argumenta quea implementação de um sistema de governança na gestão pública perpassa pela inserção de mecanismos de prestação de contas e de responsabilização das ações para garantir a apropriada accountability. Oliveira (2015) complementa afirmando que esse componente também pode ser compreendido como uma série de práticas referentes à transparência, prestação de contas e avaliação da satisfação dos stakeholders. Desse modo, oportunizar o acesso aos resultados da gestão às partes interessadas contribui para que a administração repare processos deficientes e viciosos, identificando onde podem ser melhorados (TRIBUNAL DE CONTAS DA UNIÃO, 2017).

Conforme demonstrado no Quadro 1, os mecanismos de governança pública foram associados a um conjunto de componentes que, quando executados de forma adequada, contribuem para o alcance dos objetivos e, por conseguinte, para o estabelecimento da boa governança pública. 
Quadro 1 - Componentes dos mecanismos de governança

\begin{tabular}{|c|c|}
\hline Mecanismos & Componentes \\
\hline \multirow{4}{*}{ Liderança } & Pessoas e competências \\
\hline & Princípios e comportamentos \\
\hline & Liderança organizacional \\
\hline & Sistema de governança \\
\hline \multirow{3}{*}{ Estratégia } & Relacionamento com partes interessadas \\
\hline & Estratégia organizacional \\
\hline & Alinhamento transorganizacional \\
\hline \multirow{3}{*}{ Controle } & Gestão de riscos e controle interno \\
\hline & Auditoria interna \\
\hline & Accountability e transparência \\
\hline
\end{tabular}

Fonte: TCU (2014)

Para o TCU (2014), todos os três mecanismos (liderança, estratégia e controle) podem ser analisados e devem estar alinhados com as quatro perspectivas de observação da governança no setor público, a saber: sociedade e estado; entes federativos, esferas de poder e políticas públicas; órgãos e entidades; e atividades intraorganizacionais. O objetivo é obter direcionamentos de altos níveis que se repliquem para os níveis abaixo na estrutura organizacional.

\section{Conceitos de processos}

Os processos são essenciais e estão presentes em todos os tipos de organizações; todo tipo de trabalho importante faz parte de algum processo. A ideia de processo ultrapassa a transformação de inputs em outputs e o objetivo de gerar valor ao usuário, e estende-se, também, a aspectos como o feedback e a repetibilidade (GONÇALVES, 2000).

Processo pode ser definido como um conjunto de atividades inter-relacionadas, que interagem entre si e que transformam entradas em saídas (ASSOCIAÇÃo BRASILEIRA DE NORMAS TÉCNICAS, 2005). Os processos seguem uma sequência predeterminada de atividades que conduzem a um resultado esperado para o atendimento das necessidades e expectativas dos clientes e de quaisquer partes interessadas (FNQ, 2009). Carvalho (2015) contribui para o entendimento do conceito, argumentando 
que os processos seguem certas regras e restrições, ou seja, seguem um fluxo de acordo com certos pré-requisitos.

Outra definição é de que o processo consiste no meio de organização do trabalho e dos recursos com intuito de proporcionar um resultado - produto ou serviço - e agregar valor ao cliente (SHARP; MCDERMOTT, 2009). Segundo Maranhão e Macieira (2004), o entendimento de processo está intimamente atrelado à existência de três elementos: o que será transformado (input); a transformação em si (execução do processo) e o resultado da transformação (output).

Há diversas classificações na literatura sobre os processos, entre elas a de Gonçalves (2000), que os agrupa em três categorias:

- Processos de negócio: são aqueles direcionados para a área de atuação da empresa e que são apoiados por outros processos internos, gerando um produto ou serviço que é percebido por um cliente;

- Processos organizacionais: são todos aqueles processos voltados para a organização e que viabilizam o funcionamento coordenado entre os mais diversos subsistemas da organização, garantindo desse modo o suporte adequado aos processos de negócio;

- Processos gerenciais: são os processos focados nos gerentes, e têm como objetivo a medição e ajustes de desempenho necessários na organização.

Louzada e Duarte (2013) colocam que não basta apenas possuir processos organizados - é necessário que estes estejam alinhados para a obtenção de metas comuns a todos na empresa. Isso significa que todas as partes executoras e fornecedores dos processos devem estar alinhados para a agregação de valor ao cliente.

\section{Gestão de processos e por processos}

Há na literatura e na doutrina uma distinção no que concerne ao conceito de Gestão de Processos e de Gestão por Processos. Sordi (2008) explica que a Gestão de Processos consiste em uma abordagem mais reduzida e ocorre quando se faz a gestão de um ou mais processos de forma isolada, enquanto que a Gestão por Processos consiste em uma abordagem administrativa que prioriza e trata os processos de forma sistêmica e integrada.

$\mathrm{Na}$ Gestão por Processos, as funções da organização são visualizadas a partir da sequência lógica de suas atividades e tarefas, diferentemente da abordagem funcional tradicional, na qual as organizações atuam de forma isolada, burocratizada e sem muita visão holística. (BRASIL, 2013) 
Rezende (2015) compreende que esse modelo de gestão - de processos -, entre outras coisas, permite maior clarificação das operações e responsabilidades; detectar com mais facilidade os gargalos e falhas de integração; redução de retrabalhos, que, como se sabe, além de prejudicarem a produtividade, acabam ocasionando custos e desperdícios de tempo e de recursos.

Um dos elementos mais importantes dos processos é seu gerenciamento, que pode ser realizado utilizando diversas abordagens. A mais conhecida é o Business Process Management (BPM) que se configura como um método de gerenciamento de processos de negócio, no qual conta com a assistência de ferramentas tecnológicas para seu desenvolvimento (SANTOS; DEDA; OliveIRA, 2015). O BPM é uma nova forma de observar os processos de negócio em uma organização e compreende todo o trabalho realizado com a finalidade de entregar o produto ou serviço ao cliente, entre todas as áreas envolvidas. Desse modo, o BPM presume que os objetivos organizacionais podem ser alcançados com definição, desenho, controle e transformação desses processos de negócio (ВРм Свок, 2013).

De acordo com Hammarstrom (2012), a utilização do BPM permite a modelagem, padronização e documentação dos processos, o que facilita a transmissão e disseminação de informações no âmbito da empresa e auxilia em treinamentos e na continuação das atividades por novos colaboradores, além de observar os processos de forma macro, independente da estrutura hierárquica.

\section{Processos na gestão pública}

A ideia de processos na gestão pública está intimamente ligada à apregoada eficiência administrativa, princípio introduzido no bojo constitucional com a Emenda Constitucional 19/98. Moreira Neto (2006) dispõe que tal princípio consiste em uma imposição ao Estado para que ele atenda às demandas da sociedade com a máxima qualidade e com o menor dispêndio de custos e recursos; em suma, representa que as atividades no serviço público devem ser exercidas com celeridade, adequação, presteza e com rendimento funcional.

Batista Júnior (2004) ressalta que a eficiência em âmbito público é mais complexa do que a existente no privado, pois o Estado dedica-se, precipuamente, à prestação de serviços públicos essenciais, sem finalidade lucrativa. Em geral, a mensuração do nível de eficiência é feita a partir do nível de atendimento aos objetivos previstos na lei, no ordenamento jurídico.

Em virtude do "foco no cidadão" a administração pública deve direcionar seus processos ao atendimento das necessidades da sociedade e, para isso, é imprescindível que os agentes administrativos tenham seus processos modelados, 
automatizados e geridos, de modo a viabilizar maior controle, qualidade e efetividade às iniciativas desempenhadas. Entende-se, dessa forma, que o enfoque em processos também representa uma diretriz estratégica para uma organização. (BRASIL, 2011)

O mapeamento de processos corresponde ao início do trabalho de simplificação, etapa na qual é realizado o levantamento das atividades e normas e, posteriormente, esboçado o atual fluxo do processo. É uma ferramenta que viabiliza a promoção de melhoria dos processos existentes ou mesmo a formulação de uma nova estrutura. Segundo Datz et al. (2004), sua aplicação permite a redução de custos, a identificação e solução de falhas de integração entre sistemas e possibilita melhorias no desempenho da organização.

O mapeamento de processos faz-se de grande relevância também no que concerne à transmissão e disseminação de informações e conhecimento no âmbito das organizações (REZENDE, 2015), o que perpassa a ideia de gestão do conhecimento, à medida que se busca por meio dele registrar e documentar as etapas do processo. Segundo Nonaka e Takeuchi, (2008) a Gestão do Conhecimento representa um dos mais novos e importantes recursos competitivos para as organizações.

Prado Júnior (2013) ressalta que, no âmbito da administração pública, a primeira etapa do mapeamento de processos consiste na identificação dos processos organizacionais existentes na instituição, levando em consideração a legislação vigente, a estrutura funcional do órgão e seu planejamento estratégico especialmente missão, visão, valores, objetivos e metas.

Pinho et al. (2007) afirma que diversas técnicas podem ser usadas para realização de mapeamento de processos, entre elas: mapa de processo; fluxograma; mapofluxograma; diagrama de fluxo de dados (DFD); blueprint e IDEF3. Dentre essas ferramentas, uma das mais utilizadas é o fluxograma.

A seção a seguir apresenta os procedimentos metodológicos da pesquisa.

\section{Metodologia}

Utilizando como base o conceito de Gil (2017), esta pesquisa está caracterizada como exploratória e descritiva, quanto aos seus fins, por ser um estudo com respaldo na lógica interpretativista; para estudo e análise dos dados foi realizada uma abordagem qualitativa. Quanto aos meios, de acordo com Yin (2010), caracterizase como um estudo de caso único, que permite uma investigação aprofundada e empírica de um determinado fenômeno, utilizando como base o contexto real e suas diversas variáveis de análise - no caso desta pesquisa, uma Universidade Federal brasileira localizada na região amazônica. 
A Universidade Federal do Amapá, aqui pesquisada, passa desde 2016 pela implantação de um novo sistema informatizado de gestão acadêmica e administrativa. Nesse cenário, a universidade tem direcionado seus esforços para o mapeamento, padronização e otimização de todos os seus processos. 0 método de gestão norteador utilizado pela universidade foi o BPM, e a notação de processos empregada tem sido o BPMN, por meio do software Bizagi, que é uma das ferramentas mundialmente mais utilizadas no mercado para modelagem de processos com a referida notação. A pesquisa teve como participantes e respondentes seis dos seus principais gestores da instituição e que ocupam os cargos descritos a seguir e estão classificados da seguinte forma na análise e interpretação de resultados: Reitoria (E1), Pró-Reitoria de Planejamento (E2), Pró-Reitoria de Extensão e Ações Comunitárias (E3), Pró-Reitoria de Cooperação e Relações Interinstitucionais (E4), Pró-Reitoria de Gestão de Pessoas (E5) e a PróReitoria de Ensino de Graduação (E6).

Para o estudo, foram realizadas pesquisas bibliográficas e documentais, sobretudo no Plano de Desenvolvimento Institucional (PDI) e Documentação dos Procedimentos Operacionais Padrão - POP, documento elaborado pela Pró-Reitoria de Planejamento e que tem como objetivo direcionar e padronizar o mapeamento dos processos da Universidade. Como técnica complementar de coleta dos dados, foram realizadas entrevistas semiestruturadas com os participantes, que, de acordo com Provanov e Freitas (2013) são consideradas essenciais na pesquisa qualitativa, pois têm como objetivo primário a compreensão dos significados atribuídos aos elementos e situações que não foram anteriormente estruturados e utilizam suposições do pesquisador.

Para tratamento e análise dos dados obtidos nas entrevistas, foi utilizada a técnica de análise de conteúdo, através das fases de pré-análise, exploração do material e o tratamento dos resultados e interpretação. A partir do referencial teórico utilizado optou-se por utilizar categorias de análise com base nos mecanismos e componentes de governança do setor público, definidos pelo TCU (2014), a saber: a) Liderança (pessoas e competências; princípios e comportamentos; liderança organizacional; sistema de governança); b) Estratégia (relacionamento com partes interessadas; estratégia organizacional; alinhamento transorganizacional) e c) Mecanismos de controle (gestão de riscos e controle interno; auditoria interna; accountability; transparência). Assim, após reunidas as categorias de análise, foi possível ter uma maior compreensão da metodologia de implantação dos processos na Universidade Federal do Amapá e permitido confrontar-se com a teoria utilizada.

A próxima seção traz os resultados da pesquisa, cuja coleta de dados ocorreu no primeiro semestre de 2017. 


\section{Análise e interpretação dos resultados}

Com o propósito de facilitar o entendimento sobre a gestão de processos, a análise dos resultados foi feita com base na divisão que sugere o TCU (2014), que subdivide a governança em três grandes mecanismos (liderança, estratégia e controle), que são subdivididos nos respectivos componentes:

\section{Mecanismo estratégia}

Inicialmente, buscou-se compreender junto aos entrevistados as principais justificativas para a implementação de uma gestão de processos na Unifap. A partir do relato dos entrevistados, foi possível perceber que, entre os principais motivos que fundamentam essa ação, estão "identificar e conhecer", além de "definir fluxos e uniformizar" os processos da instituição. Isso está de acordo com Paim (2007) quando este cita que entre os primeiros passos para a implementação de processos em uma instituição estão entender o ambiente da organização, bem como distinguir e eleger os principais processos a serem mapeados.

Corroborando para esse entendimento, o entrevistado E5 relatou que o gerenciamento de processos permite "maior rapidez na resposta às demandas da comunidade acadêmica e do público interno". Salgado et al. (2013) contribui com esse entendimento citando que as universidades públicas, por serem organizações complexas, carecem de um gerenciamento de processos mais eficiente para a prestação de um serviço com mais qualidade.

Os hábitos organizacionais do setor público contribuem para a rigidez e burocratização dos serviços (BIAZZI; MUSCAT; BIAZZI, 2011). Os autores ainda citam a execução do trabalho por parte dos servidores em "modus operandi", com ligação extrema a regras e legislação, sem levantar questionamentos sobre a melhor forma de realização das atividades. Nesse aspecto, os entrevistados justificam a implementação de uma gestão de processos para dar celeridade na tramitação desses, além de reduzir retrabalhos e empoderar os servidores que executarão os procedimentos, fazendo-os refletir quanto ao melhor caminho e andamento dos processos.

Desse modo, a partir dessas exposições iniciais, ficou perceptível o que os gestores esperam quanto à implementação de uma gestão de processos, visando ao maior conhecimento e padronização das rotinas e fluxos operacionais, além de oferecer maior celeridade nas respostas às demandas da sociedade.

O tema processos foi citado na construção do Plano de Desenvolvimento Institucional (PDI) da Unifap (2015), na condição de objetivo estratégico "aprimorar os processos operacionais e gerenciais", relacionado à perspectiva de processos 
internos. Ao serem questionados quanto à contribuição da Gestão de Processos para o alcance de objetivos elencados no PDI, os gestores citaram "maior eficiência administrativa" e "a facilidade para atingir as metas que foram estabelecidas" como fatores preponderantes para uma melhor gestão. Em conformidade com o assunto, o TCU (2015) aponta que os indicadores têm o poder de mensurar e esclarecer informações sobre o desempenho da estratégia.

É de grande importância que as organizações tenham capacidade de conhecer seu atual desempenho utilizando parâmetros de medidas que forneçam informações e deem embasamento ao gestor para uma tomada de decisão mais precisa e imediata revisão de inconsistências (BRASIL, 2016).

Acerca da contribuição dos processos para o alcance das metas estabelecidas no PDI, o E4 menciona entre as vantagens o estabelecimento de indicadores, os quais, de acordo com o E3, também viabilizam a maior integração entre ensino, pesquisa e extensão. Portanto, conforme exposto, o mapeamento de processos e a criação de indicadores para os mesmos têm impacto direto em um objetivo estratégico específico, como também influenciam indiretamente em outros aspectos do PDI, como "reduzir custos operacionais", "fortalecer a política de governança corporativa" e "avaliar e acompanhar o desenvolvimento institucional". Nesse sentido, pode-se perceber que os gestores reconhecem a importância do mapeamento de processo para a consecução dos objetivos elencados no PDI.

O relacionamento com as partes interessadas é um dos componentes constituintes do mecanismo estratégia, abordado neste tópico. Desse modo, quando questionados sobre como o mapeamento de processos pode facilitar a comunicação e acesso de informação das partes interessadas, os gestores elencaram "clareza e transparência de como os processos são desenvolvidos", "disseminação do conhecimento" e "permitir o acompanhamento por parte dos usuários (interno e externo)" como benefícios resultantes do mapeamento de processos.

Portanto, com base no exposto podemos inferir que o mapeamento e a divulgação dos processos ajudarão a gestão da Unifap a se comunicar melhor com a comunidade acadêmica, dando autonomia ao usuário, disponibilizando as informações corretas, regulares, acertadas, passando, desse modo a desconectar o conhecimento individual para o conhecimento institucional. Nesse sentido, Evangelista (2010) evidencia que os cidadãos estão saindo da condição de "clientes" para a situação de "sócios" do Estado, agindo como parceiros e exercendo maior controle e fiscalização quanto às atividades exercidas. Desse modo, as pessoas tornam-se mais conscientes em relação ao seu poder de influência nas políticas públicas, bem como à importância do acompanhamento das atividades. 
Uma facilidade citada pelo E4 sobre a comunicação com as partes interessadas é a possibilidade de redução de falhas; outro benefício apontado pelo E2 diz respeito à redução do desencontro de informações entre os envolvidos. Diante do relatado, a comunicação na gestão pública deve primar pelo fluxo de informações que são do interesse coletivo e individual, permitindo o diálogo efetivo entre as organizações, as pessoas que a compõem e a sociedade (LEMOS, 2011).

Quando perguntados em relação a como sua pró-reitoria/reitoria pode contribuir no estabelecimento de mecanismos de Benchmarking, os gestores citaram as visitas técnicas a instituições de referência em processos como forma de viabilizar a capacitação dos servidores que executam atividades de natureza similar, como forma de captar aprendizado quanto às melhores práticas. $\mathrm{O}$ gestor E4 ressalta que a participação efetiva em eventos de grande relevância sobre a temática em instituições referência na referida área podem potencializar e aprimorar a gestão de processos na universidade. Aires et al. (2012) discorrem sobre o tema enfatizando que as organizações de serviços públicos de ensino devem buscar o aperfeiçoamento contínuo de seus processos, seja aprimorando seus processos ou adotando práticas diferenciadas, tornando isso elemento primordial para a melhoria dos serviços prestados à comunidade acadêmica.

Com base nisso, entende-se que a administração da universidade pode e está fazendo uso de práticas inovadoras na gestão, sendo que essas práticas podem transcender a área de processos e convergir de maneira eficaz em outras funções como treinamento de servidores, processos de avaliação de desempenho, entre outros.

\section{Mecanismo de controle}

Iniciando com a categoria controle, buscou-se observar a forma como se realizará o controle e o acompanhamento dos processos já mapeados e dos que serão implementados. Os gestores citaram a ocorrência de reuniões de avaliação e, especificamente o E2, cita a possibilidade de criação de um módulo específico no Sipac (Sistema integrado de patrimônio, administração e contratos), e o E5 acrescenta que a verificação do desempenho desses processos no sistema poderá ser mais eficiente.

O Gespública (BRASIL, 2014) propõe a avaliação e monitoramento pela mais alta instância de governança interna da organização, para que, dessa forma, possa ser feito o controle observando regulamentos e legalidade, a concordância com a conduta sugerida e a melhor execução das atividades.

A verificação e a gerência dos processos são um passo fundamental para a prestação de serviços com cada vez mais qualidade, visto que essa ação permite 
a elaboração de medidas corretivas nos fluxos processuais, assim como a identificação de falhas e retrabalhos. Nesse sentido, percebe-se que os gestores possuem estratégias razoáveis para o acompanhamento e controle dos processos da universidade.

Procedendo com a temática, foi examinado de que maneira o mapeamento pode dar mais transparência aos processos para os clientes, fornecedores da Unifap e órgãos reguladores (TCU, MEC, etc). Os entrevistados apontaram como principais pontos a interação com a comunidade e o acompanhamento de suas demandas pela mesma. Desse modo, observa-se que os processos podem proporcionar maior transparência e permitir uma melhor orientação de como as atividades são executadas, do seu passo a passo e das responsabilidades de quem as executa.

Evangelista (2010) corrobora com o apresentado afirmando que a disponibilização das informações sustenta um maior controle social. O gestor E1 acrescenta que uma contribuição do mapeamento é a accountability, que surge como uma nova forma de posicionar o servidor público, em consonância com Silva et al. (2016), que argumenta que esse servidor deve ser colocado como líder e portador do interesse público, ressaltando que é indispensável a participação dos cidadãos para que a accountability seja funcional. Nota-se que a participação do servidor como agente-cidadão que forneça as informações é essencial para a concretização de uma prestação de contas acertada, sendo também primordial o acompanhamento pelo restante da sociedade.

A última questão dessa categoria buscava identificar a percepção dos gestores quanto à contribuição do mapeamento e a padronização de processos na avaliação da eficiência e eficácia do desempenho dos processos. As respostas mais citadas apontaram a busca por novas maneiras de resolver os conflitos como auxílio do mapeamento de processos e, como notado pelos E1 e E2, mensurar o tempo médio da execução dos processos.

Com os processos mapeados, torna-se mais claro identificar onde há retrabalhos ou erros que fazem o processo retornar ou ficar parado. A mensuração dos processos deve ser constante e periódica, indicando e prevendo possíveis necessidades de redesenho do processo, além disso, as oportunidades de melhoria devem ser apresentadas às partes interessadas para análise e avaliação, resultando na atualização sistemática (PRADO JúNIOR, 2013).

Contudo, nota-se a falta de elaboração de outros indicadores para o acompanhamento do desempenho dos processos. A elaboração de indicadores é uma etapa essencial para verificação dos resultados e redesenho das atividades falhas no processo (FAdUL; SILVA, 2008; JESTON; NELIS, 2006). 


\section{Mecanismo de liderança}

O último mecanismo investigado foi o de liderança, que diz respeito a uma série de práticas que asseguram as condições para o exercício da governança. Relacionado a esse mecanismo, buscou-se verificar se houve algum processo de sensibilização dentro das pró-reitorias para a implantação do POP e, no caso de resposta positiva, de que forma se deu essa sensibilização.

Observa-se que, na grande maioria das pró-reitorias, a sensibilização ocorreu por meio de reuniões nas quais foram discutidas questões relativas ao mapeamento. O gestor E4 relatou que sua pró-reitoria passou por capacitação sobre gestão de processos, ocasiões em que foram expostos os principais conceitos de mapeamento de processos e as técnicas que seriam utilizadas na universidade.

Outro ponto importante, destacado por E2, é que o projeto nasceu de uma iniciativa do nível estratégico da universidade (top-down), sendo o desafio engajar os demais níveis da universidade. Essa abordagem vai de encontro com os resultados encontrados por Moreira (2015), que observou o contrário do fato aqui citado. A liderança na organização é um fator crucial para o sucesso na implantação do projeto, seja liderando o processo ou fornecendo um cenário onde o mesmo possa acontecer por meio de suporte, financiamento e empenho (Jeston; Nelis, 2008).

Divergindo do que foi afirmado pelos demais entrevistados, o gestor E6 discorre que não houve reuniões indutivas na pró-reitoria, e relata também que os servidores têm baixa procura e motivação em relação ao mapeamento de processos. Jeston e Nelis (2008) destacam que uma das mudanças cruciais é no posicionamento dos líderes quanto à motivação da equipe, seu conhecimento e habilidades que serão transmitidos ao grupo. Nota-se que as reuniões indutivas e de treinamento surtiram efeito satisfatório aos que fizeram o uso, entretanto, nem todos os setores tiveram o mesmo interesse.

Dando prosseguimento à temática liderança, foi analisado de que forma o mapeamento de processos pode ajudar no balanceamento de poder entre as estruturas administrativas (pró-reitorias, divisões, setores) da universidade. Acerca do assunto, os entrevistados fizeram referência à descentralização de poder e à tomada de decisão. Segundo o E1, o mapeamento viabiliza maior autonomia; já E3 destaca o empoderamento aos participantes dos processos. Tôrres (2005) argumenta que no passado havia uma visão mecanicista a respeito das organizações, onde líderes eram providos de poder e conduziam o conjunto de tarefas a serem executadas por cada unidade. Entretanto, essa visão passou a ser substituída conforme o passar do tempo, buscando não somente um líder, mas pessoas com autodomínio e destaque para resolver conflitos e inconsistências 
conforme o andamento das atividades, agregando valor não somente ao "fim" dos processos, mas também durante todo o andamento do mesmo.

Portanto, percebe-se a preocupação dos gestores em reavaliar os papéis na tomada de decisão e o alinhamento das competências e responsabilidades das partes interessadas nos processos. Isso está de acordo com TCU (2014) quando coloca que a consecução de um bom sistema de governança perpassa necessariamente pela análise criteriosa das estruturas organizacionais presentes na instituição.

$\mathrm{Na}$ compreensão de E6, a partir da identificação de responsabilidades e competências, os processos tendem a ser mais facilmente mapeados. Tal fato é essencial no que diz respeito à definição de quem executará determinadas atividades, podendo ser utilizada como instrumento de controle, verificando se a atividade foi realizada por seu responsável. De acordo com Silva (2014), na implementação de uma gestão de processos, deve-se conferir responsabilidades à equipe para a tomada de decisão necessária, de modo a evitar a concentração de poder na mão de poucos participantes do processo (TRIBUNAL DE CONTAS DA UNIÃO, 2014).

Com o intuito de identificar o envolvimento da equipe nesse processo de implementação do POP, os entrevistados foram questionados quanto ao engajamento e participação dos servidores no mapeamento de processos, e quais as dificuldades e resistências encontradas. A maioria dos gestores afirmou que há engajamento e participação dos servidores no mapeamento.

Porém, para o E1 não há engajamento da equipe, pois o mecanismo motivacional empregado não surtiu o efeito desejado aos servidores. Outro ponto relevante afirmado pelo E6 de maneira enfática é que não há motivação, proatividade, compromisso ou interesse por parte dos servidores. Um dos fatores citados pelo entrevistado, e ressaltado pelo $\mathrm{E} 1$, como possíveis causas dessas inconformidades, é a falta da força de vontade dos servidores. A respeito disso, Carvalho (2015, p. 31) registra que um dos fatores críticos para o êxito na implantação de uma gestão por processos está em modificar as "atitudes e perspectivas" das pessoas que avaliam, bem como as que executam os processos.

Outro ponto citado é a falta de liderança presente e motivacional, que possivelmente pode desencadear o desinteresse dos servidores pelo mapeamento. Medeiros e Gutierrez (2015) argumentam que não basta apenas o comprometimento da equipe, mas também a presença de um líder que inspire credibilidade e confiança aos demais. 
O alinhamento com outros setores da universidade foi uma dificuldade citada pelos entrevistados E4 e E5. Tal característica também foi observada por Rodrigues (2015), sendo que, quanto maior for a quantidade e a complexidade de processos com envolvimento de diversos atores, mais difícil será seu alinhamento. Esse fato pode ser entendido observando a abordagem de transição de uma gestão funcional para uma gestão de processos. O conceito de processo transversal, que busca integrar as atividades do início ao fim do processo, é desconhecido no modelo funcional, em que o processo só é visualizado dentro de uma unidade funcional (PAIM et al., 2009).

O último questionamento dessa categoria buscou extrair a percepção dos gestores quanto à relação entre gestão dos processos (mapeamento) e a conduta ética dos servidores da universidade. A impessoalidade foi um dos itens citados, sendo potencializada com o mapeamento. O E2 citou o processo de licitação como exemplo, em que a falta de algumas etapas, como publicação ou elaboração de pareceres acarretaram em falha do processo e, quando se tem isso institucionalizado e descrito com clareza, está-se atendendo a diversos princípios atrelados à ética, inclusive a impessoalidade.

Por meio dos relatos, notou-se a preocupação dos gestores E1 e E6 quanto à execução de determinadas atividades essenciais para a legalidade do processo, e à sua descrição detalhada como forma de garantir a execução dos trâmites obrigatórios e impedir eventuais desvios éticos. Fortini e Sherman (2017) contribuem com esse entendimento, afirmando que uma das particularidades mais importantes da governança está na sua ênfase na prevenção de condutas desviantes, e não em sua repressão. Portanto, uma preocupação da governança é evitar eventuais inconsistências, e a gestão de processos pode contribuir com isso descrevendo as atividades e o fluxo do processo para maior entendimento dos atores que nele estão envolvidos.

Acerca disso, o E3 menciona o comprometimento e a conduta profissional dos servidores, no sentido de empenhar-se em errar menos e buscar corrigir os erros, além de buscar transmitir o conhecimento dos processos para outrem, de modo a tornar possível que mais de uma pessoa saiba executar o processo.

Por fim, buscou-se identificar a percepção dos gestores quanto ao mapeamento e a gestão de processos e sua contribuição à Unifap na profissionalização da sua gestão e no fortalecimento dos mecanismos de governança pública (liderança, estratégia e controle). Entre os itens observados, o mais citado pelos entrevistados E3, E4, E5 e E6 foi a maturidade e segurança na execução dos processos, com a diminuição do amadorismo e da pessoalidade e amadurecimento da gestão. 
A criação de uma memória organizacional também foi citada pelos gestores, no que diz respeito à produção contínua do fluxo do trabalho, independentemente do perfil de liderança do gestor. A memória organizacional é um importante componente da gestão do conhecimento (FREIRE et al., 2012), e permite a manutenção das rotinas de trabalho e das melhores práticas exercidas pelas equipes passadas (MAGALHÃEs et al., 2014), sendo que a retenção do conhecimento garante que a execução dos processos, entre outros, não seja afetada ou postergada caso o especialista do processo deixe a organização (Helmann; Carvalho, 2007).

O fortalecimento da equidade, por meio do equilíbrio de poder entre os setores, foi relatado pelos E1 e E2. Nesse sentido, o E2 acrescenta que a equidade consiste no tratamento isonômico dado à informação, sendo a mesma para todos a partir do mapeamento, que também foi um dos benefícios encontrados por Moreira (2015). Portanto, o mapeamento permite a divulgação e o acesso igualitário aos stakeholders do processo, considerando que as instituições públicas contemplam também a sociedade.

\section{Mecanismos e componentes}

No Quadro 2, estão destacados os pontos considerados mais relevantes orientados pelos mecanismos e seus respectivos componentes, na perspectiva dos gestores da Universidade Federal do Amapá. 
Quadro 2 - Pontos relevantes por categoria de análise

\begin{tabular}{|c|c|c|c|}
\hline MECANISMO & COMPONENTES & QUESTIONAMENTO & $\begin{array}{l}\text { PONTOS } \\
\text { RELEVANTES }\end{array}$ \\
\hline \multirow{4}{*}{ Estratégia } & $\begin{array}{l}\text { Relacionamento } \\
\text { com partes } \\
\text { interessadas }\end{array}$ & $\begin{array}{l}\text { Como o mapeamento de } \\
\text { processos pode facilitar } \\
\text { a comunicação e acesso } \\
\text { de informação das partes } \\
\text { interessadas }\end{array}$ & $\begin{array}{l}\text { Clareza e } \\
\text { transparência sobre } \\
\text { como os processos } \\
\text { são desenvolvidos; } \\
\text { disseminação do } \\
\text { conhecimento; } \\
\text { permitir o } \\
\text { acompanhamento } \\
\text { por parte dos } \\
\text { usuários; redução de } \\
\text { falhas e desencontro } \\
\text { de informações. }\end{array}$ \\
\hline & \multirow[b]{2}{*}{$\begin{array}{l}\text { Estratégia } \\
\text { organizacional }\end{array}$} & $\begin{array}{l}\text { Contribuição da Gestão de } \\
\text { Processos para o alcance de } \\
\text { objetivos elencados no PDI }\end{array}$ & $\begin{array}{l}\text { Maior eficiência; } \\
\text { facilitar o } \\
\text { atingimento das } \\
\text { metas estabelecidas } \\
\text { no PDI; integrar } \\
\text { ensino, pesquisa } \\
\text { e extensão; } \\
\text { estabelecer } \\
\text { indicadores. }\end{array}$ \\
\hline & & $\begin{array}{l}\text { Principais justificativas para } \\
\text { a implementação de uma } \\
\text { gestão de processos na } \\
\text { Unifap }\end{array}$ & $\begin{array}{l}\text { Celeridade; definir } \\
\text { fluxos; uniformizar, } \\
\text { aprimorar e } \\
\text { reduzir retrabalhos } \\
\text { nos processos; } \\
\text { empoderamento; } \\
\text { conhecer e } \\
\text { identificar os } \\
\text { processos; maior } \\
\text { rapidez na resposta. }\end{array}$ \\
\hline & $\begin{array}{l}\text { Alinhamento } \\
\text { transorganizacional }\end{array}$ & $\begin{array}{l}\text { Considerações a respeito } \\
\text { de como sua pró-reitoria/ } \\
\text { reitoria pode contribuir } \\
\text { no estabelecimento } \\
\text { de mecanismos de } \\
\text { benchmarking }\end{array}$ & $\begin{array}{l}\text { Visitas técnicas; } \\
\text { participação em } \\
\text { eventos de grande } \\
\text { relevância. }\end{array}$ \\
\hline
\end{tabular}




\begin{tabular}{|c|c|c|c|}
\hline \multirow{3}{*}{ Controle } & $\begin{array}{l}\text { Gestão de riscos e } \\
\text { controle interno }\end{array}$ & $\begin{array}{l}\text { Realização do controle e } \\
\text { o bbompanhamento dos } \\
\text { processos já mapeados } \\
\text { e dos que serão } \\
\text { implementados }\end{array}$ & $\begin{array}{l}\text { Publicidade dos } \\
\text { processos; sistema } \\
\text { interno; correção } \\
\text { imediata de } \\
\text { falhas durante os } \\
\text { processos. }\end{array}$ \\
\hline & Auditoria interna & $\begin{array}{l}\text { Contribuição do } \\
\text { mapeamento e a } \\
\text { padronização de processos } \\
\text { na avaliação da eficiência } \\
\text { e eficácia do desempenho } \\
\text { dos processos }\end{array}$ & $\begin{array}{l}\text { Mensuração do } \\
\text { tempo médio dos } \\
\text { processos; buscar } \\
\text { novas maneiras de } \\
\text { resolver conflitos }\end{array}$ \\
\hline & $\begin{array}{l}\text { Accountability e } \\
\text { transparência }\end{array}$ & $\begin{array}{l}\text { De que maneira o } \\
\text { mapeamento pode dar } \\
\text { mais transparência aos } \\
\text { processos para os clientes, } \\
\text { fornecedores da Unifap e } \\
\text { órgãos reguladores (TCU/ } \\
\text { MEC etc) }\end{array}$ & $\begin{array}{l}\text { Interação com } \\
\text { a comunidade; } \\
\text { acompanhamento } \\
\text { das demandas; } \\
\text { accountability. }\end{array}$ \\
\hline \multirow{4}{*}{ Liderança } & $\begin{array}{l}\text { Pessoas e } \\
\text { competências }\end{array}$ & $\begin{array}{l}\text { Processo de sensibilização } \\
\text { dentro das pró-reitorias } \\
\text { para a implantação do } \\
\text { POP, no caso de resposta } \\
\text { positiva, de que forma se } \\
\text { deu essa sensibilização. }\end{array}$ & $\begin{array}{l}\text { Reuniões de indução } \\
\text { e sensibilização. }\end{array}$ \\
\hline & $\begin{array}{l}\text { Princípios e } \\
\text { comportamentos }\end{array}$ & $\begin{array}{l}\text { Relação entre gestão dos } \\
\text { processos (mapeamento) } \\
\text { e a conduta ética dos } \\
\text { servidores da universidade }\end{array}$ & $\begin{array}{l}\text { Impessoalidade, } \\
\text { comprometimento e } \\
\text { conduta profissional } \\
\text { dos servidores. }\end{array}$ \\
\hline & $\begin{array}{l}\text { Liderança } \\
\text { organizacional }\end{array}$ & $\begin{array}{l}\text { Engajamento e participação } \\
\text { dos servidores no } \\
\text { mapeamento de processos, } \\
\text { e quais as dificuldades e } \\
\text { resistências encontradas }\end{array}$ & $\begin{array}{l}\text { Engajamento dos } \\
\text { servidores na } \\
\text { maioria dos setores; } \\
\text { dificuldade de } \\
\text { alinhamento. }\end{array}$ \\
\hline & $\begin{array}{l}\text { Sistema de } \\
\text { governança }\end{array}$ & $\begin{array}{l}\text { De que forma o } \\
\text { mapeamento de processos } \\
\text { para balanceamento de } \\
\text { poder entre as estruturas } \\
\text { administrativas (pró- } \\
\text { reitorias, divisões, setores) }\end{array}$ & $\begin{array}{l}\text { Descentralização do } \\
\text { poder e tomada de } \\
\text { decisão; autonomia; } \\
\text { empoderamento; } \\
\text { alinhamento; } \\
\text { definição de } \\
\text { responsabilidades e } \\
\text { competências. }\end{array}$ \\
\hline
\end{tabular}

Fonte: Dados da pesquisa (2017). 
O Quadro 2 apresenta os pontos relevantes de cada categoria de análise de acordo com os pontos mais citados pelos gestores, elencando os principais benefícios da implantação da gestão de processos na instituição pesquisada e sua relação com a liderança, estratégia e controle, apresentados pelo TCU (2014) como mecanismos para o alcance da boa governança pública. Percebe-se que, na perspectiva dos gestores, os processos possuem grande relevância no que concerne à divulgação de informações às partes interessadas (transparência) e também para compreender como auxiliam no alcance dos objetivos definidos no PDI da Universidade, além de mostrarem a importância de uma liderança adequada para a motivação e alinhamento dos setores em prol do mapeamento.

Sugere-se, com base nos relatos dos gestores, que os processos mapeados sejam utilizados como uma ferramenta de controle na diminuição de erros e retrabalhos, na mensuração da performance e na accountability. Por fim, observa-se seu impacto nas pessoas, seja no fortalecimento da impessoalidade ou na construção das relações de poder.

\section{Considerações finais}

No contexto atual, marcado pela necessidade de transparência e prestação de contas, a utilização e o fortalecimento dos mecanismos de governança pública tornam-se imprescindíveis à otimização da gestão institucional - inclusive das IFES. A partir da implementação efetiva de um sistema de governança, torna-se possível prestar serviços à sociedade, utilizando os recursos públicos eficientemente, de modo a garantir e promover o bem-estar e desenvolvimento social. Nesse sentido, o objetivo geral do estudo foi identificar as relações existentes entre os mecanismos de governança pública do TCU e a implementação de uma gestão de processos no âmbito da Universidade Federal do Amapá.

A partir de uma análise qualitativa, identificou-se a relação existente entre a adoção de uma gestão de processos na Unifap e os mecanismos de governança do TCU (2014). No mecanismo estratégia, foi possível verificar, por meio do estudo bibliográfico e relato dos entrevistados, que é essencial o esforço e interesse da alta administração para uma implementação adequada de uma gestão de processos, onde os administradores possam ser capazes de produzir resultados mensuráveis a partir dos processos, facilitando a avaliação e produzindo conhecimento para todos os envolvidos.

Apesar de não ter iniciado utilizando como base os mecanismos de governança pública apresentados no TCU (2014), a implementação de uma gestão de processos na Unifap, especificamente o mapeamento de processos, apresenta 
finalidades e objetivos que incidirão no fortalecimento da governança pública nessa instituição, proporcionando maior eficiência, interação com a comunidade e maior controle social.

A utilização do mapeamento de processos na referida instituição demonstra, também, forte ligação com os princípios da administração pública, em especial em uma instituição de Ensino Superior Federal, que tem como prioridade a formação de cidadãos voltados à prosperidade social e ao desenvolvimento regional. Essa ação promove o fortalecimento do princípio da impessoalidade, por meio da descrição detalhada de cada atividade, dos respectivos responsáveis e do trâmite apropriado ao processo, assegurando que cada etapa seja cumprida conforme prescrita, obstruindo o uso de quaisquer benefícios ou entraves.

Ao vincular o mapeamento de processos com o mecanismo de liderança, é notório que os setores que obtiveram maior êxito em qualidade e volume de processos mapeados contam com uma administração que lida melhor com os servidores e comunidade, reforçando que o empenho de todos os participantes, desde os que mapeiam, executam e avaliam é fator essencial para o sucesso da gestão de processos.

Em relaçãoao mecanismo de controle, os resultados apontaram que asferramentas que serão utilizadas para acompanhamento dos processos proporcionarão maior controle social, tanto no acompanhamento das demandas por parte do usuário, quanto na identificação e correção de falhas de atividades específicas. Porém, no presente, não se percebe o uso efetivo dessas ferramentas, podendo-se citar o uso não aprofundado do sistema de gestão integrado da universidade; apesar de este ter sido implantado recentemente, há módulos específicos para o acompanhamento de processos que não estão sendo devidamente utilizados.

Isso sugere uma incompatibilidade entre o que foi relatado pelos gestores e o recomendado pelo TCU (2014), uma vez que os gestores valorizam a transparência e a publicidade dos processos relacionados aos mecanismos de estratégia e controle, mas ainda não efetuam de maneira intensa a publicação desses.

A importância deste estudo é correlacionar duas temáticas essenciais para a administração pública: processos e governança. Constata-se, por meio dos resultados obtidos com o estudo, que a gestão de processos é um meio que viabiliza a efetividade da governança. Nesse sentido, usuários internos e também a comunidade externa tornam-se beneficiários, pois, à medida que os processos são devidamente mapeados, é possível promover elementos norteadores como transparência, eficiência, conduta profissional, impessoalidade, bem como assegurar o acompanhamento por parte dos usuários (controle social), que, em uma abordagem maior, também estão entre os objetivos da governança pública. 
Uma limitação do trabalho tem relação com o tempo de implementação do mapeamento de processos, ou seja, os relatos dos gestores estão relacionados a perspectivas, pois os processos não foram totalmente disponibilizados e validados para uma parcela da comunidade acadêmica (docentes e discentes), embora tenham sido apresentados para os gestores e técnicos-administrativos da Universidade e suas respectivas pró-reitorias.

Recomenda-se, para pesquisas futuras, fazer uma análise dos resultados obtidos com a implantação de todos os processos, analisando a percepção dos gestores envolvidos, bem como dos demais membros da comunidade acadêmica, docentes, discentes e técnicos-administrativos.

\section{Referências bibliográficas}

AIRES, R. et al. Benchmarking de escolas de governo do Brasil: proposta de melhoria para a Escola de Serviço Público do Estado da Paraíba - Espep. Sistemas \& Gestão, São Paulo, v. 7, n. 4, p. 570-583, 2012. LATEC. http://dx.doi.org/10.7177/sg.2012. v7., n4.a5.

ASSOCIAÇÃO BRASILEIRA DE NORMAS TÉCNICAS. NBRISO 9000: sistema de gestão da qualidade - fundamentos e vocabulários. Rio de Janeiro: ABNT, 2005.

BATISTA JÚNIOR, O. Princípio constitucional da eficiência administrativa. Belo Horizonte: Mandamentos, 2004.

BıAZZı, M. R. de; Muscat, A. R. N.; BıAZZı, J. L. Modelo de aperfeiçoamento de processos em instituições públicas de ensino superior. Gestão \& Produção, São Paulo, v. 18, n. 4, p. 869-880, 2011. FapUnifesp (Scielo). http://dx.doi.org/10.1590/ s0104-530x2011000400013.

Врм Свок, A. Guia para o Gerenciamento de Processos de Negócio Corpo Comum de Conhecimento. São Paulo: Association of Business Process Management Professionals Brazil, 2013. 453 p.

BRASIL. Manual do Conselheiro de Administração. Brasília: Secretaria de Coordenação e Governança das Empresas Estatais - Sest, 2017. 40 p.

BRASIL. Construindo e gerenciando indicadores: guia metodológico. Brasília: Superior Tribunal de Justiça, 2016. 94 p.

BRASIL. Programa Gespública: modelo de excelência em gestão pública. Brasília: MP/Segep, 2014.

BRASIL. Escritório de Processos Organizacionais do MPF. Manual de Gestão por Processos. Brasília: MPF/PGR, 2013. 73 p.

BRASIL. Guia de Gestão de Processos do Governo: Áreas de integração para governo eletrônico, arquitetura e-PING de inteporabilidade. Brasília: Sepro, 2011. 93 p.

BRASIL. Decreto no 5.378, de 23 de fevereiro de 2005. Institui o Programa Nacional de Gestão Pública e Desburocratização - GESPÚBLICA e o Comitê Gestor do Programa Nacional de Gestão Pública e Desburocratização, e dá outras providências. Brasília, 
2005. Disponível em <http://www.planalto.gov.br/ccivil_03/_ato2004-2006/2005/ decreto/d5378.htm> Acesso em 08 nov. 2017.

CAMpos, Renata Alves; LIMA, Sandra Maria Peron De. Mapeamento de Processos: Importância para as organizações, 2012. Disponível em: http://www.ufrrj.br/codep/ materialcursos/projetomapeamento/MapeamentoProcesso s.pdf

CARVALHo, K. A.; SoUSA, J. C. Gestão por processos: novo modelo de gestão para as instituições públicas de ensino superior. Revista Administração em Diálogo - Rad, São Paulo, v. 19, n. 2, p. 1-15, 1 maio 2017. Portal de Revistas PUC SP. http://dx.doi. org/10.20946/rad.v19i2.25298.

CARVAlho, K. Gestão por processos organizacionais na Universidade de Brasília: estudo de caso. 2015. 147 f. Dissertação (Mestrado) - Curso de Gestão Pública, Universidade de Brasília, Brasília, 2015.

DATZ, D.; Melo, A. C. S.; FernANDES, E. Mapeamento de processos como instrumento de apoio à implementação do custeio baseado em atividades nas organizações. In: Encontro Nacional de Engenharia de Produção, 24., 2004, Foz do Iguaçu. Anais... Foz do Iguaçu: Enegep, 2004. p. 1-15.

EvangelistA, L. Controle social versus transparência pública: uma questão de cidadania. 2010. 34 f. Monografia (Especialização) - Curso de Orçamento Público, Tribunal de Contas da União, Brasília, 2010.

FADUL, E.; SILVA, L. Retomando o debate sobre a reforma do Estado e a nova gestão pública. In: Encontro Nacional de Pós-GraduAção E PESQUISA EM AdMINISTRAÇÃo, 23., 2008, Rio de Janeiro. Anais... São Paulo: Anpad, 2008. p. 1-16.

FortinI, C.; Shermam, A. Governança pública e combate à corrupção: novas perspectivas para o controle da administração pública brasileira. Int. Públ, São Paulo, v. 19, n. 2, p. 27-44, jun. 2017.

FREIRE, P. et al. Memória organizacional e seu papel na gestão do conhecimento. Revista Ciências da Administração, Florianópolis, v. 14, n. 33, p. 41-51, jun. 2012.

Fundação Nacional da QuALIDAde (FNQ). Critérios de excelência. São Paulo: FNQ, 2009.

GIL, A. Como elaborar projetos de pesquisa. 6. ed. São Paulo: Saraiva, 2017.

GonçALVES, J. As empresas são grandes coleções de processos. Rae - Revista de Administração de Empresas, São Paulo, v. 40, n. 1, p. 6-19, jan. 2000.

HAMMARSTROM, R. Automação na tramitação de processos em instituições públicas. 2012. 100 f. Dissertação (Mestrado) - Curso de Engenharia Mecânica, Universidade de Taubaté, Taubaté, 2012.

helmann, C.; Carvalho, H. Práticas de gestão do conhecimento que promovem a retenção de conhecimento tecnológico no setor de pesquisa e desenvolvimento. In: Encontro Nacional de Engenharia de Produção, 27., 2007, Foz do Iguaçu. Anais... Foz do Iguaçu: Enegep, 2007. p. 1-10. InSTITUTO BRASILEIRO DE GovERNANÇA CORPORATIVA (IBGC). Código das melhores práticas de governança corporativa. 5. ed. São Paulo: IBGC, 2015. 108 p. 
INTERNATIONAL FEDERATION OF Accountants (IFAC). Good governance in the public sector: consultation draft for an international framework. Nova lorque: International Public Sector Study, 2013.

JESTON, J.; NELIS, J. Business process management: practical guidelines to successful implementations. Burlington: Elsevier, 2008.

KRÜGER, M. Maturidade em governança com base nas práticas recomendadas pelo TCU: estudo de caso em um tribunal regional do trabalho. 2016. 123 f. Dissertação (Mestrado) - Curso de Mestrado, Instituto Superior de Administração e Economia (Isae), Curitiba, 2016.

LÉLIS, D.; MARIO, P. D. C. Auditoria interna com foco em governança, gestão de riscos e controle interno: análise da auditoria interna de uma empresa do setor energético. In: CONGRESSO USP - CONTROLADORIA E CONTABILIDADE, 1., 2009, São Paulo. Anais... São Paulo: Congresso USP, 2009. p. 1-14.

LEMOS, V. O processo de comunicação na gestão pública na prefeitura da cidade de São José dos Campos. 2011. 40 f. Monografia (Especialização) - Curso de Gestão Pública Municipal, Universidade Federal Tecnológica do Paraná, São José dos Campos, 2011.

LOUZADA, C.; DUARTE, A. Gestão por processo: estudo de caso em uma empresa de varejo de colchões. Rev. Científica Eletrônica Uniseb, Ribeirão Preto, v. 1, n. 1, p. 36-53, jan. 2013.

MAgalhãES, T.; DAlmaU, M.; SouZA, I. Gestão do conhecimento para tomada de decisão: um estudo de caso na empresa júnior. Revista de Gestão Universitária da América Latina-Gual, Florianópolis, v. 7, n. 2, p. 108-129, jun. 2014.

Maranhão, M.; MACIEIRA, M. O processo nosso de cada dia: modelagem de processos de trabalho. Rio de Janeiro: Qualitymark, 2004.

MARTINS, H. F.; MARINI, C. Um guia de governança para resultados na administração pública. Brasília: Publix Conhecimento, 2010.

Matias-PereirA, J. A governança corporativa aplicada no setor público brasileiro. Administração Pública e Gestão Social, Viçosa, v. 1, n. 2, p. 109-134, jun. 2010.

Medeiros, L.; GUTIERREZ, R. O mapeamento de processos como fator de melhoria da gestão acadêmica de uma universidade federal. In: CONGRESSO NACIONAL DE EXCELÊNCIA EM GESTÃo, 11., 2015, Rio de Janeiro. Anais... Rio de Janeiro: Cneg, 2015. p. 1-19.

MelLo, G. Governança corporativa no setor público federal brasileiro. 2006. 127 f. Dissertação (Mestrado) - Curso de Ciências Contábeis, Universidade de São Paulo, São Paulo, 2006.

MORAES FILHO, M. A transparência como instrumento de democracia na governança pública brasileira. Ffbusiness, Fortaleza, v. 13, n. 16, p. 1-16, jun. 2015

MoREIRA, Elzeni Alves. Gestão e mapeamento de processos nas instituições públicas: um estudo de caso na diretoria de administração de pessoal da Universidade Federal do Rio Grande do Norte. 2015. 110 f. Dissertação (Mestrado) - Curso de Gestão Pública, Universidade Federal do Rio Grande do Norte, Natal, 2015. 
Moreira Neto, D. F. Curso de Direito Administrativo. Rio de Janeiro: Forense, 2006. NASCIMENTO, L.; AGUIAR, J. Governança corporativa aplicada à gestão pública: uma análise das práticas de governança no processo de gestão da Universidade Federal de Uberlândia. In: UFU, 1., 2015, Uberlândia. Anais... Uberlândia: UFU, 2015. p. 1-18. NonAKA, I.; TAKEUCHI, H. Gestão do conhecimento. Porto Alegre: Bookman, 2008. ORGANIZAÇÃo DE COOPERAÇÃo E DE DESENVOLVIMENTO ECONÔMICO (OCDE). Liderança e Setor Público no Século 21: Governança. Brasília: Seges, 2002. 128 p.

OliveirA, S.; Neto, M. Análise e modelagem de processos de negócio: foco na notação BPMN (Business Process Modeling Notation). São Paulo: Atlas, 2009.

OliveIRA, Alden Mangueira de. Governança no setor público sob o prisma do controle externo: a experiência do Tribunal de Contas da União (TCU) na avaliação das políticas públicas e na indução do seu aperfeiçoamento como alavanca ao desenvolvimento nacional. 2015. 178 f. TCC (Graduação) - Curso de Curso de Altos Estudos de Política e Estratégia, Escola Superior de Guerra (esg), Rio de Janeiro, 2015.

PAIM, R. et al. Gestão de processos: pensar, agir e aprender. Porto Alegre: Bookman, 2009.

PAIM, R. As tarefas para gestão de processos. 2007. 498 f. Tese (Doutorado) - Curso de Doutorado em Ciência em Engenharia da Produção, Coppe/UFRJ, Rio de Janeiro, 2007.

Penedo, F.; Quelhas, O. Práticas de governança pública: aspectos da liderança em institutos de previdência municipal. In: EngEMA, 16., 2016, São Paulo. Anais... São Paulo: Engema, 2016. p. 1-16.

Pinho, A.; MonteVeCHI, J.; AlmeidA, D. Combinação entre as técnicas de fluxograma e mapa de processos no mapeamento de um processo produtivo. In: ENCONTRO Nacional de Engenharia de Produção (Enegep), 27., 2007, Foz do Iguaçu. Anais... Foz do Iguaçu: Enegep, 2007. p. 1-11.

PRADo JUNIOR, Tarcísio. Gestão por processos: instrumento de governança na administração pública. 2013. 48 f. TCC (Graduação) - Curso de Curso de Altos Estudos de Política e Estratégia, Escola Superior de Guerra (ESG), Rio de Janeiro, 2013.

Provanov, C.; FreitAs, E. Metodologia do trabalho científico: métodos e técnicas da pesquisa e do trabalho acadêmico. 2. ed. Novo Hamburgo: Feevale, 2013.

REIS, G. Modelagem de processos de negócios com BPMN: curso completo. São Paulo: Portal Bpm Ltda, 2008. 105 p.

REZENDE, J. Balanced Scorecard e a gestão do capital intelectual. 6. ed. São Paulo: Elsevier Trade/profissional, 2015. 328 p.

RODRIGUES, G. O. Aplicação da gestão de processos em uma universidade pública do estado de São Paulo. 2015. 116 f. Dissertação (Mestrado) - Mestre em Engenharia de Produção, Universidade Estadual Paulista Júlio de Mesquita Filho, Bauru, 2015.

SAlgAdo, C. et al. Contribuições à melhoria de processos organizacionais: uma avaliação empírica sob a perspectiva de mapeamento de processos em uma unidade 
da Universidade Federal da Paraíba. Holos, Natal, v. 29, n. 1, p. 151-169, jan. 2013. SAntos, A. F. C.; DedA, R. R.; OliveirA, A. A. Identificação de ontologias com BPM no ambiente da saúde: uma revisão sistemática. Revista Eletrônica de Gestão Organizacional, Recife, v. 13, n. 1, p. 176-186, jun. 2015.

SCOlforo, R. Lei de acesso à informação e governança pública no município de Lavras: fatores favoráveis e limitantes. 2013. 144 f. Dissertação (Mestrado) - Curso de Mestrado Profissional em Administração Pública, Universidade Federal de Lavras, Lavras, 2013.

SECCHI, L. Modelos organizacionais e reformas da administração pública. Revista de Administração Pública, São Paulo, v. 43, n. 2, p. 347-369, jun. 2009.

SHARP, A; MCDERMOTT, P. Workflow modeling: tools for process improvement and application development. Norwood: Artech House, 2009.

SILVA, A. et al. Aplicação da accountability na administração pública no Brasil. In: Encontro AcAdÊMico FAcPed, 10., 2016, Fortaleza. Anais... Fortaleza: Facped, 2016. p. 22-28.

SILVA, R.; SENNA, E.; LIMA JUNIOR, O. Governança pública: dimensões e atributos de desempenho aplicados à governança de plataformas logísticas. Revista Alcance Eletrônica, Itajaí, v. 21, n. 1, p. 98-125, jun. 2014.

SILVA, J. O mapeamento de processos organizacionais no setor público: estudo de caso do escritório de processos da Agência Nacional de Vigilância Sanitária (Anvisa). 2014. 59 f. TCC (Graduação) - Curso de Bacharel em Gestão de Políticas Públicas, Universidade de Brasília, Brasília, 2014.

SORDI, J. Gestão por processos: uma abordagem da moderna administração. 2. ed. São Paulo: Saraiva, 2008.

TRIBUNAL DE CONTAS DA UnIÃo (TCU). Referencial de combate a fraude e corrupção: Aplicável a Órgãos e Entidades da Administração Pública. Brasília: Secretaria de Métodos e Suporte ao Controle Externo (Semec), 2017. 132 p.

TRIBUnal de CONTAS dA União (TCU). Plano estratégico do Tribunal de Contas da União: 2015 - 2021. Brasília: TCU, 2015. 96 p.

TRIBUNAL DE CONTAS DA UNIÃO (TCU). Governança pública: referencial básico de governança aplicável a órgãos e entidades da administração pública e ações indutoras de melhoria. Brasília: Secretaria de Planejamento, Governança e Gestão, 2014. 98 p.

TÔRRES, J. Teoria da complexidade: uma nova visão de mundo para a estratégia. Integra Educativa, Valparaíso, v. 2, n. 2, p. 189-202, 2005.

Universidade Federal do AMAPÁ. Plano de Desenvolvimento Institucional (PDI): 2015-2019. Macapá: Unifap, 2015. 113 p.

YIN, R. Estudo de caso: planejamento e métodos. Porto Alegre: Bookman, 2010. 248 p. ZucATTO, L. et al. Proposição de indicadores de desempenho na gestão pública. Contexto, Porto Alegre, v. 16, n. 9, p. 1-24, jun. 2009. 


\section{Alan Carlos Pereira da Costa}

Discente do oitavo semestre do curso de bacharelado em Administração pela Universidade Federal do Amapá. Atua como consultor na área de processos organizacionais. Contato: costaalan95@gmail.com

\section{Ana Flavia Pacheco Leal}

Bacharel em Administração pela Universidade Federal do Amapá, atua na área bancária. Contato: ana.leal1404@ gmail.com

\section{Lana Caroline Barbosa do Nascimento}

Bacharel em Administração pela Universidade Federal do Amapá, Servidora do Poder Executivo Federal na Unifap, cargo Administradora. Contato: lananascimento15@gmail.com

\section{Cláudio Márcio Campos de Mendonça}

Doutor em Administração pela Universidade Federal do Rio Grande do Norte, atua como professor do magistério superior na Universidade Federal do Amapá, Campus Marco Zero. Contato: cmarcio@gmail.com

\section{Lenin Cavalcanti Brito Guerra}

Doutor em Administração pela Universidade Federal do Rio Grande do Norte, atua como professor do magistério superior no Instituto Federal de Educação, Ciência e Tecnologia do Rio Grande do Norte, Campus Natal Central. Contato: guerra04@gmail.com 
RSP 